\title{
Getting our house in order
}

\author{
Tony Delamothe deputy editor, The BMJ
}

\begin{abstract}
Anyone with even a fleeting acquaintance with The $B M J$ will have noticed the words "oseltamivir" (Tamiflu) and "statins" appearing a lot recently. With two online collections devoted to the drugs (thebmj.com/tamiflu and thebmj.com/statins), it may seem that we've developed an unhealthy obsession with them. What we're obsessed with is getting sight of the evidence for oseltamivir's efficacy and statins' adverse effects. It could have been any drug; it's just that these showed up on our radar first.
\end{abstract}

Alteplase would make an equally worthy candidate for closer scrutiny of both risks and benefits, as our News story shows (doi:10.1136/bmj.h3301). Roger Shinton and three other senior clinicians have called on the health secretary for England to get unpublished trial data on alteplase released into the public domain. Until that happens, they say, the routine use of alteplase for ischaemic stroke should be suspended.

Such fighting talk can lose friends as well as influence people, we've noticed. As reported last week, England's chief medical officer, Sally Davies, wrote to the Academy of Medical Sciences decrying recent controversies that "had damaged the public's faith in the way research was carried out and presented" (doi:10. 1136/bmj.h3300). Oseltamivir and statins both received special mentions. "Reluctantly," Davies concluded, "we do need an authoritative independent report looking at how society should judge the safety and efficacy of drugs as an intervention."

Into the breach has stepped the academy, an intriguing development given that it's one of the few similar outfits not to have come out in favour of the AllTrials campaign (alltrials. net), which calls for all clinical trials to report their results. The academy has promised to report back by the end of the year on its "Evaluating evidence" project. Meanwhile, we at The BMJ are unrepentant: we want all data that underpin decision making about medical interventions to be publicly available, along with the competing interests of the decision makers. We can't see any alternative. Failure risks endangering the public's trust in science, without which doctors may as well pack up and go home. So the ultimate destination cannot be in doubt, even if the timescale is a bit hazy. What is of interest now is who obstructs, who facilitates.

We asked Ben Goldacre and Carl Heneghan, founders of AllTrials, for their thoughts on the Academy of Medical Sciences' impending review. They worry that the academy may accept shortcomings in the evidence as inevitable (doi:10.1136/ bmj.h3397). As an alternative, they describe six "simple practical improvements" that the academy could endorse and that would alleviate legitimate concerns. "The public is increasingly aware of the shortcomings we collectively tolerate in the evidence base for clinical practice," they warn. The time has come to "get our house in order."

Evidence that balancing the risks and benefits of drugs is not solely a UK preoccupation comes from Prescrire, a French cousin of our own Drug and Therapeutics Bulletin. Each year its editors assess new drugs entering the French market. Its dismal tally for 2014 was that three "offered a real advance," five "offered an advantage," 15 were "possibly helpful," 35 brought "nothing new," and 19 were "not acceptable" (doi:10. 1136/bmj.h3325).

Many houses, much disorder.

Cite this as: BMJ 2015;350:h3432

๑ BMJ Publishing Group Ltd 2015 